\title{
FORMULASI BISNIS MODEL SURAT KABAR ELEKTRONIK DI PIKIRAN RAKYAT
}

\author{
Aditia Sovia Pramudita1 , Amri Yanuar², Tamadara Hilman ${ }^{3}$ \\ Program Studi Logistik Bisnis, Politeknik Pos Indonesia Email: \\ aditiasovia@poltekpos.ac.id
}

\begin{abstract}
Newspaper industry in fact is decreasing from 2006 until right now. Shifting behavior of their customer is becoming newspaper company problem to survive in this industry. Newspaper industry should shift their business into e-newspaper if they did not want to end up like music distributor industry. Even though, e-newspaper business model itself is not easy to be adapt. In fact, there are a lot of newspaper company who already failed to implement e-newspaper. Most of newspaper company treat e-newspaper only as their other distribution channel. It was the wrong concept if they want to develop e-newspaper and run it as the substitution of traditional newspaper. Revenue stream become the main concern in e-newspaper since it is difficult to create sustainable revenue stream. Result of the research is in order to create sustainable revenue stream, newspaper company should take a look at their resources and capabilities first. Value chain analysis is used to grab the potency of Pikiran Rakyat and make it as value proposition concerning e-newspaper in order to create revenue stream through e-newspaper. Last, business model canvas is used in order to map the proposed business model. In the end, e-newspaper Pikiran Rakyat has various revenue stream that could be used.
\end{abstract}

Keywords: E-newspaper, Value Chain Analysis, Business Model Canvas

\begin{abstract}
Abstrak
Industri surat kabar mengalami penurunan sejak 2006 hingga saat ini. Perubahaan perilaku pelanggan merupakan masalah utama perusahaan surat kabar untuk dapat bertahan di industri ini. Industry surat kabar sendiri harus mampu memindahkan bisnis utama mereka dari surat kabar tradisional menjadi surat kabar elektronik jika mereka tidak ingin berakhri seperti industri distributor musik. Namun demikian, bisnis model surat kabar elektronik sendiri sulit untuk diadaptasi. Banyak perusahaan surat kabar yang telah gagal mengimpelemntasikan surat kabar elektronik. Kebanyakan perusahaan surat kabar hanya memperlakukan surat kabar elektronik sebagai salah satu saluran distribusi mereka saja. Hal tersebut merupakan konsep yang salah jika mereka menginginkan surat kabar elektronik untuk berkembang dan menggantikan surat kabar cetak. Revenue stream menjadi masalah utama di dalam surat kabar elektronik dikarenakan untuk mencetak revenue melalui surat kabar elektronik sangatberbeda dengan surat kabar cetak. Hasil dari penelitian ini adalah, dalam rangka penciptaan revenue stream yang berkelanjutan, perusahaan surat kabar perlu untuk melihat sumber daya dan kapabilitas mereka terlebih dahulu. Analisis rantai nilai digunakan untuk dapat melihat potensi dari Pikiran Rakyat dan membuat hal tersebut menjadi value proposition di dalam bisnis model surat kabar elektronik yang kemudian bertujuan untuk menciptakan revenue stream. Business model canvas digunakan untuk memetakan bisnis model usulan. Pada akhirnya, Pikiran Rakyat memiliki beberapa pilihan revenue stream yang dapat digunakan pada bisnis model surat kabar elektronik mereka.

Kata Kunci: Surat Kabar Elektronik, Analisis Rantai Nilai, Business Model Canvas
\end{abstract}




\section{PENDAHULUAN}

Belakangan ini teknologi internet telah mempengaruhi distribusi dari barang dan jasa. Hal ini merupakan konsekuensi untuk industri surat kabar agar dapat menciptakan revolusi dalam dunia jurnalisme (Guo \& Sun, 2004). Dengan adanya sistem informasi yang baru dapat mempercepat proses penerimaan berita kepada pembacanya, biaya distribusi dan kesempatan untuk bisa berhubungan langsung dengan para pembacanya (Flavian \& Gurrea, 2009). Perkembangan ini membuat suatu jenis baru dalam industri surat kabar yang ditunjukan dengan adanya electronic newspaper atau sering disebut e-newspaper.

Kondisi surat kabar tidak jauh berbeda dengan kondisi pada industri musik ataupun video. Minat masyarakat saat ini terhadap surat kabar cetak semakin menurun dari tahun ke tahunnya. Menurut serikat perusahaan pers, total pembaca surat kabar pada awal 2006 mencapai $25.1 \%$ kini telah menurun menjadi 15\% (Republika, 2011). Survey Tingkat konsumsi media ini dilakukan Nielsen Media Research pada tahun 2014 di 5 wilayah kota besar di luar Jawa yaitu Medan, Palembang, Denpasar, Makassar dan Banjarmasin dan di 5 wilayah kota besar di Jawa yang meliputi Jakarta dan Bodetabek dan Gerbangkertasila (Kabupaten Gresik, Kabupaten Bangkalan, Kabupaten Mojokerto, Kota Mojokerto, Kota Surabaya, Kabupaten Sidoarjo, Kabupaten Lamongan),Bandung, Semarang, Yogyakarta dan Sleman- Bantul.

Gambar 1 Jumlah Pembaca Koran 10 Kota di Indonesia

Sumber: Nielsen, 2015

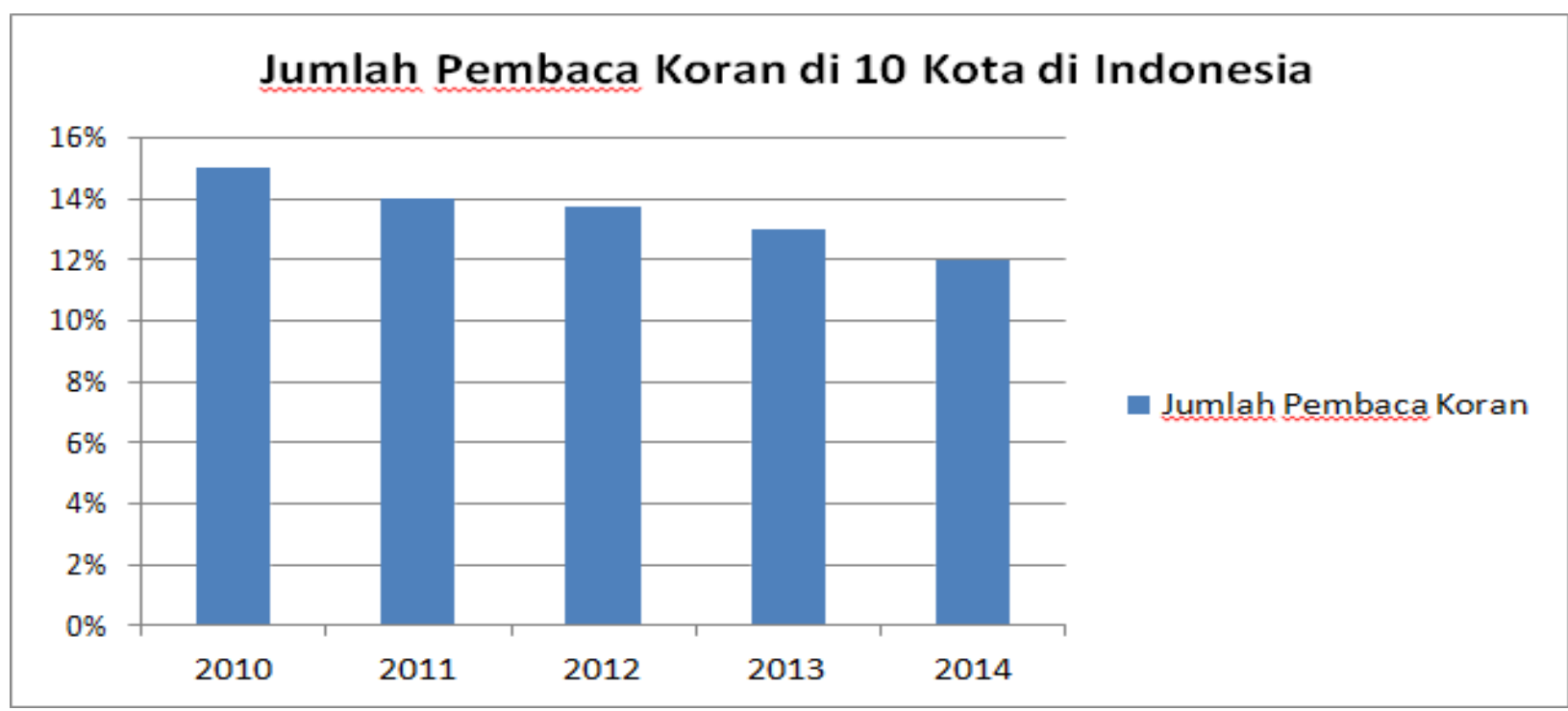

Berdasarkan grafik diatas dapat dilihat bahwa jumlah pembaca surat kabar cetak yang dijadikan sampel oleh Nielsen dari 10 wilayah di Indonesia semakin menurun lima tahun terakhir. Yang semula pada tahun 2010 sebesar 15\%, tahun 2011 sebesar 14\%, tahun 2012 sebesar 13,7\%, tahun 2013 sebesar 13\% dan 12\% di tahun 2014. Hal ini menunjukan pembaca surat kabar cetak dalam lima tahun terakhir mengalami penurunan. Dari fakta diatas dapat ditarik kesimpulan bahwa saat ini produk surat kabar cetak sudah memasuki tahap decline. Hal tersebut disebabkan oleh masuknya media-media berita ataupun hiburan online. Penggunaan media online yang lebih mudah membuat surat kabar cetak secara perlahan mulai ditinggalkan. Namun demikian peminat surat 
kabar cetak sendiri tidak akan hilang. Berdasarkan hasil survey yang dilakukan Nielsen pada tahun 2015, 58\% dari konsumen surat kabar cetak memilih surat kabar karena dianggap dapat memberikan berita yang dapat dipercaya. Hal tersebut menunjukan bahwa surat kabar akan tetap memiliki pasarnya sendiri selama paradigm konsumen terhadap kualitas berita di surat kabar tidak berubah. Namun demikian perusahaan surat kabar tetap perlu untuk mengikuti perubahan jaman dengan cara memasuki media online. Perilaku konsumen surat kabar saat ini telah mengalami pergeseran selama beberapa tahun kebelakang. Generasi muda lebih memilih surat kabar digital dibandingkan dengan surat kabar cetak (Kulturdepartementet, 2010). Generasi muda sebagai konsumen potensial surat kabar merupakan segmen yang penting bagi perusahaan surat kabar untuk terus dikejar. Perusahaan surat kabar perlu untuk beradaptasi terhadap perilaku konsumsi mereka agar dapat meraih pangsa pasar yang lebih baik. Dengan adanya e-newspaper merupakan sebuah langkah yang tepat untuk bisa merengkuh segmen tersebut. Namun demikian perusahaan surat kabar perlu untuk mengubah bisnis model mereka, khususnya e-newspaper, dengan tujuan untuk bisa memperkenalkan secara luas kepada masyarakat agar terbiasa menggunakan enewspaper dan mendapatkan revenue dari e-newspaper itu sendiri.

\section{METODE PENELITIAN}

Menurut Pearce \& Robinson (2008) istilah Value Chain (Rantai Nilai) menggambarkan cara untuk memandang suatu perusahaan sebagai rantai aktivitas yang mengubah input menjadi output yang bernilai bagi pelanggan.Nilai bagi pelanggan berasal dari tiga sumber dasar : aktivitas yang membedakan produk, aktivitas yang menurunkan biaya produk dan aktivitas yang dapat segera memenuhi kebutuhan pelanggan. VCA berupaya memahami bagaimana suatu bisnis menciptakan nilai bagi pelanggan dengan memeriksa kontribusi dari aktivitas- aktivitas yang berbeda dalam bisnis terhadap nilai tersebut.

Menurut Pearce \& Robinson (2008), VCA mengambil sudut pandang proses. Analisis ini membagi/memecah bisnis menjadi kelompok-kelompok aktivitas yang terjadi dalam bisnis tersebut, diawali dengan input yang diterima oleh perusahaan dan berakhir dengan produk atau jasa perusahaan dan layanan purna jual bagi pelanggan. VCA berupaya melihat biaya lintas rangkaian aktivitas yang dilakukan oleh bisnis tersebut untuk menentukan dimana terdapat keunggulan biaya rendah atau kelemahan biaya. VCA melihat kepada atribut-atribut dari setiap aktivitas yang berbeda ini untuk menentukan dengan cara bagaimana setiap aktivitas yang terjadi antara pembelian input dan layanan purna jual dapat membedakan produk atau jasa perusahaan.

Gambar dibawah memperlihatkan kerangka rantai nilai dasar / umum (Pearce \& Robinson, 2008) Kerangka ini membagi aktivitas dalam perusahaan menjadi dua kategori umum yaitu aktivitas utama dan aktivitas pendukung. Aktivitas utama adalah aktivitas yang terlibat dalam penciptaaan pisik produk, pemasaran dan transfer ke pembeli, serta layanan purna jual. Aktivitas pendukung adalah aktivitas yang membantu perusahaan secara keseluruhan dengan menyediakan infrastruktur atau input yang memungkinkan aktivitas-aktivitas utama dilakukan secara berkelanjutan. Rantai nilai ini mencakup margin laba karena markup di atas `biaya perusahaan untuk menyediakan aktivitas bernilai tambah umumnya merupakan bagian dari harga yang dibayar oleh pembeli- menciptakan nilai yang melampaui biaya untuk menghasilkan imbalan atas upaya tersebut. Dibutuhkan penilaian pribadi untuk setiap perusahaan dan industri yang berbeda karena apa yang di pandang sebagai aktivitas pendukung oleh suatu perusahaan mungkin merupakan aktivitas primer bagi perusahaan lain atau industri lain. 


\section{Business Model Canvas}

Bisnis model menjelaskan mengenai dasar pemikiran bagaimana sebuah bisnis diciptakan, diberikan, dan ditangkap nilainya (Osterwalder, 2010). Osterwalder \& Pigneur membuat sebuah pendekatan model kanvas yaitu "Nine Building Blocks" yang memudahkan bagi para pebisnis untuk membangun dan mengembangkan bisnis mereka. Nine Building Blocks terdiri dari: Value Proportions, Customer Segments, Customer Relationship, Channels, Key Resources, Key Activity, Key Partnership, Cost Structure, dan Revenue Stream.

Menurut Osterwalder \& Pigneur (2010, hal 138-139), ide inovasi dalam bisnis model dapat datang dari mana saja. Osterwalder \& Pigneur membedakan inovasi model bisnis menjadi lima bagian yaitu: Resource- driven, Offer-driven, Customer-driven, Finance-driven, dan Multipleepicenter. Resource-driven adalah inovasi yang berasal dari infrastruktur yang ada dalam sebuah organisasi atau memperluas dalam kemitraan atau mengubah sebuah model bisnis. Offer-driven adalah inovasi yang dibuat menciptakan nilai proporsi yang baru yang dapat memberikan dampak kepada building blocks bisnis model yang lain. Customer-driven adalah inovasi yang didasarkan pada kebutuhan pelanggan, memfasilitasi akses, atau meningkatkan kenyamanan. Finance-driven adalah inovasi yang memberikan aliran penghasilan yang baru, mekanisme penetapan harga, atau mengurangi strukur biaya yang dapat mempengaruhi pada building blocks lainnya. Multipleepicenter adalah inovasi yang didorong oleh banyak faktor yang dapat memberikan dampak signifikan terhadap beberapa building blocks lainnya.

Adapun template untuk membuat sebuah bisnis model canvas dapat dilihatpada gambar dibawah ini.

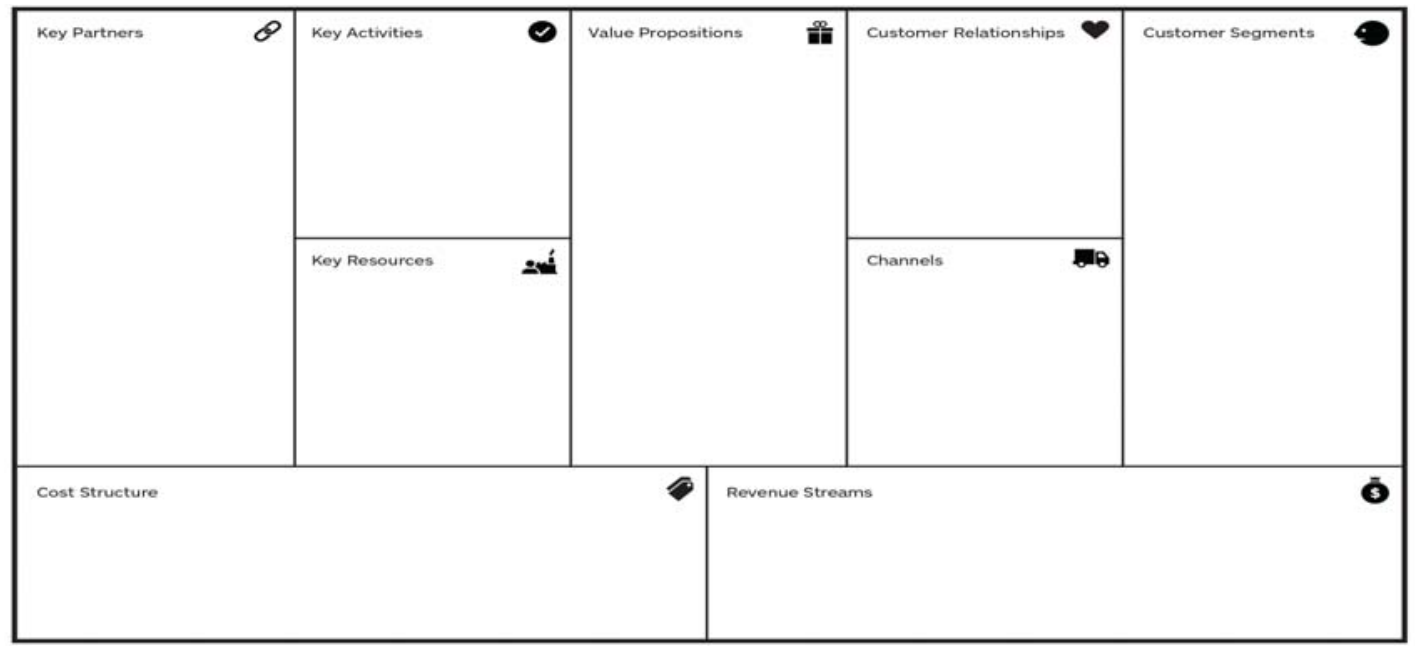

Gambar 2 Template Bisnis Model Canvas

Sumber: Business Model Generation, 2010

\section{Penelitian Terdahulu}

Berikut akan dipaparkan penelitian terdahulu yang menjadi landasan dalam penelitian ini, serta sebagai acuan untuk mecari pola sebagai dasar pembaharuan dalam kajian penelitian terkait. 
Tabel 1 Penelitian Terdahulu

\begin{tabular}{|c|c|c|c|c|c|}
\hline $\begin{array}{l}\mathbf{N} \\
\mathbf{0}\end{array}$ & Judul & Penulis & Tahun & $\begin{array}{l}\text { Metode } \\
\text { Penelitian }\end{array}$ & Hasil Penelitian \\
\hline 1 & $\begin{array}{l}\text { A } \\
\text { business } \\
\text { model } \\
\text { for the } \\
\text { e- } \\
\text { newspa } \\
\text { per from } \\
\text { a } \\
\text { custome } \\
\text { r } \\
\text { perspect } \\
\text { ive }\end{array}$ & $\begin{array}{l}\text { Ton } \\
\text { AM } \\
\text { Spil } \\
\text { dan } \\
\text { Martijn } \\
\text { Suijker } \\
\text { buijk }\end{array}$ & 2015 & $\begin{array}{l}\text { Metode yang } \\
\text { digunakan } \\
\text { adalah metode } \\
\text { penghitungan } \\
\text { statistik } \\
\text { deskriptif. } \\
\text { Penelitian ini } \\
\text { digunakan } \\
\text { untuk } \\
\text { mengetahui } \\
\text { value } \\
\text { proposition } \\
\text { surat kabar dari } \\
\text { sudut pandang } \\
\text { konsumen }\end{array}$ & $\begin{array}{l}\text { Hasil dari penelitian ini menunjukan } \\
\text { bahwa pengguna surat kabar elektronik } \\
\text { yang potensial berusia antara } 21-25 \\
\text { tahun dan } 52-54 \text { tahun. } \\
\text { Penelitian dilakukan di Belanda. Bagi } \\
\text { potensial konsumen yang merupakan } \\
\text { generasi muda memiliki kecenderungan } \\
\text { untuk memilih surat kabar elektronik } \\
\text { dibandingkan dengan surat kabar, } \\
\text { sedangkan generasi tua mereka } \\
\text { menganggap tidak ada perbedaan antara } \\
\text { surat kabar elektronik dan surat kabar } \\
\text { cetak }\end{array}$ \\
\hline 2 & $\begin{array}{l}\text { Digital } \\
\text { Challen } \\
\text { ges on } \\
\text { the } \\
\text { Norweg } \\
\text { ian } \\
\text { Media } \\
\text { Scene }\end{array}$ & $\begin{array}{l}\text { Rune } \\
\text { Ottosen } \\
\& \\
\text { Anne } \\
\text { H. } \\
\text { Krums } \\
\text { vik }\end{array}$ & 2012 & $\begin{array}{l}\text { Metode yang } \\
\text { digunakan } \\
\text { adalah metode } \\
\text { literature } \\
\text { review. } \\
\text { Penelitian ini } \\
\text { digunakan } \\
\text { untuk } \\
\text { menyimpulkan } \\
\text { bagaimana } \\
\text { pergerakan } \\
\text { media } \\
\text { khususnya } \\
\text { media online }\end{array}$ & $\begin{array}{l}\text { Berdasarkan hasil penelitian tersebut, } \\
\text { ditekankan bahwa perusahaan surat } \\
\text { kabar harus dapat memikirkan bentuk } \\
\text { jurnalistik yang berbeda untuk surat } \\
\text { kabar elektronik bila dibandingkan } \\
\text { dengan surat kabar cetak. Hal tersebut } \\
\text { merupakan penentu konsumen akan } \\
\text { berpindah dari surat kabar cetak ke surat } \\
\text { kabar } \\
\text { elektrik }\end{array}$ \\
\hline 3 & $\begin{array}{l}\text { How } \\
\text { Business } \\
\text { Models } \\
\text { in the } \\
\text { Newspa } \\
\text { per } \\
\text { Industry } \\
\text { are } \\
\text { Selected }\end{array}$ & $\begin{array}{l}\text { Ingri } \\
\text { d } \\
\text { Hog } \\
\text { nalan } \\
\text { d }\end{array}$ & 2014 & $\begin{array}{l}\text { Metode yang } \\
\text { digunakan } \\
\text { adalah metode } \\
\text { kualitatif dan } \\
\text { kuantitatif. } \\
\text { Penelitian ini } \\
\text { bertujuan untuk } \\
\text { membuat }\end{array}$ & $\begin{array}{l}\text { Berdasarkan hasil penelitian ditemukan } \\
\text { bahwa pelanggan potensial surat kabar } \\
\text { sebenarnya datang dari generasi muda } \\
\text { dimana prilaku pembelian mereka pun } \\
\text { sudah bergeser menjadi konsumen media } \\
\text { online. Hal ini membuat surat kabar } \\
\text { harus dapat bertransformasi menjadi } \\
\text { surat kabar online. untuk dapat } \\
\text { memperoleh revenue dari surat kabar } \\
\text { online, perusahaan surat kabar perlu } \\
\text { untuk membuat surat kabar mereka }\end{array}$ \\
\hline
\end{tabular}




\begin{tabular}{|c|c|c|c|c|c|}
\hline & $\begin{array}{l}\text { and } \\
\text { Innovate } \\
\text { d }\end{array}$ & & & $\begin{array}{l}\text { formulasi bisnis } \\
\text { model surat } \\
\text { kabar yang } \\
\text { inovatif. }\end{array}$ & $\begin{array}{l}\text { menjadi eksklusif dimana konsumen } \\
\text { harus membayar atau berlanggan untuk } \\
\text { bisa melihat konten dari berita di surat } \\
\text { kabar tersebut. }\end{array}$ \\
\hline 4 & $\begin{array}{l}\text { From } \\
\text { Strateg } \\
\text { y to } \\
\text { Busine } \\
\text { ss } \\
\text { Model } \\
\text { s and } \\
\text { to } \\
\text { Tactics }\end{array}$ & $\begin{array}{l}\text { Ramon } \\
\text { Casade } \\
\text { sus and } \\
\text { Masan } \\
\text { ell } \\
\text { Joan } \\
\text { Enric } \\
\text { Ricart }\end{array}$ & 2009 & $\begin{array}{l}\text { Metode yang } \\
\text { digunakan } \\
\text { adalah studi } \\
\text { kasus. } \\
\text { Penelitian ini } \\
\text { bertujuan untuk } \\
\text { memberikan } \\
\text { sebuah } \\
\text { framework kerja } \\
\text { pembuatan } \\
\text { rencana taktis } \\
\text { dari sebuah } \\
\text { bisnis model }\end{array}$ & $\begin{array}{l}\text { Framework kerja yang dapat digunakan } \\
\text { untuk merancang rencana taktis dari } \\
\text { sebuah bisnis model }\end{array}$ \\
\hline
\end{tabular}

\section{Kerangka Pemikiran}

Dewasa ini pertumbuhan pembaca surat kabar semakin menurun dari tahun ke tahunnya. Hal tersebut diakibatkan oleh adanya pergeseran prilaku konsumen yang terdahulu terbiasa untuk mengkonsumsi surat kabar cetak menjadi mengkonsumsi berita melalui media online. Hal ini mengakibatkan perusahaan surat kabar perlu untuk bisa beradaptasi dengan perubahan yang ada di industri surat kabar ini. Berdasarkan pengamatan, beberapa perusahaan surat kabar di Indonesia sudah mulai menambah distribution channel mereka melalui pembuatan e- newspaper. Sayangnya hanya beberapa surat kabar yang terlihat dapat menghasilkan revenue melalui e-newspaper, sedangkan kebanyakan perusahaan surat kabar masih menganggap e- newspaper hanya sebagai pelengkap distribution channel mereka. Jika melihat pada kenyataan dilapangan, pergeseran prilaku pembelian ini harus dapat ditanggulangi oleh perusahaan suratkabar sehingga dari enewspaper ini perusahaan dapat tetap menghasilkan revenue yang pasti sehingga perusahaan akan dapat tetap hidup. Untuk dapat merancang bisnis model yang tepat bagi perusahaan surat kabar ini, analisis rantai nilai dan bisnis model eksisting e-newspaper sangatlah diperlukan agar dapat merancang bisnis model baru yang lebih tepat sasaran. Adapun kerangka pemikiran pada penelitian ini dapat dilihat pada gambar di bawah ini. 


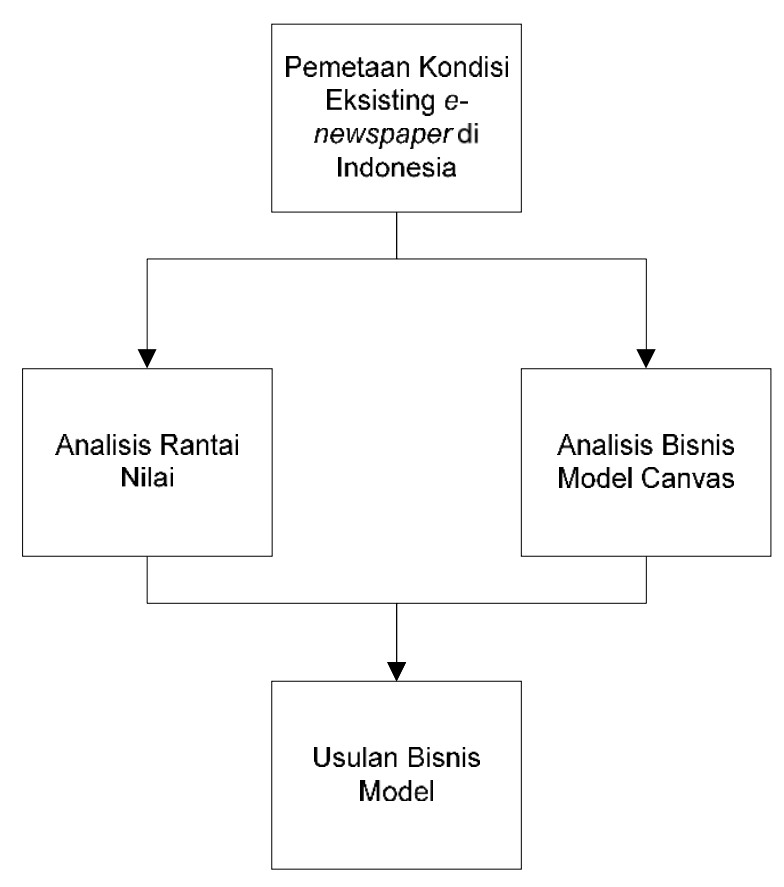

Gambar 4 Kerangka Pemikiran

Permasalahan yang dikaji disini bersifat dinamis sehingga pemilihan metode kualitatif dianggap dirasa cocok untuk menjawab permasalahan diatas. Penelitian kualitatif digunakan untuk dapat memahami proses bisnis di surat kabar khususnya surat kabar elektronik dengan cara observasi dan wawancara mendalam dengan pihak-pihak terkait dan para ahli.

\section{HASIL PENELITIAN DAN PEMBAHASAN}

Value Chain Analysis merupakan tools untuk menganalisis kegiatan internal perusahaan. Analisis ini berfungsi untuk mengungkap dimana keunggulan dan kekurangan suatu perusahaan (Porter, 1985). Hal tersebut perlu diketahui agar dapat memetakan kekuatan dan kelemahan perusahaan terhadap e newspaper Pikiran Rakyat. Untuk melakukan analisis ini, wawancara dilakukan terhadap Wakil Kepala Urusan yang mengacu terhadap konsep Value Chain Analysis.

\section{Primary Activity}

\section{- $\quad$ Inbound Logistics}

Inbound logistics Pikiran Rakyat adalah bagaimana pergerakan barang/ jasa sebagai raw material untuk diproses di Pikiran Rakyat. Raw material di Pikiran Rakyat adalah konten berita yang diperoleh dari Jurnalis Pikiran Rakyat maupun dari Kontributor. Proses mendapatkan raw material tersebut dilakukan dengan cara Jurnalis maupun Kontributor menyerahkan konten berita yang akan diangkat kepada Pikiran Rakyat.

\section{- Operations}

Proses operasi di e newspaper tidak terlepas dari newspaper fisik. Proses bisnis secara umumnya dapat dilihat pada gambar di bawah ini. 


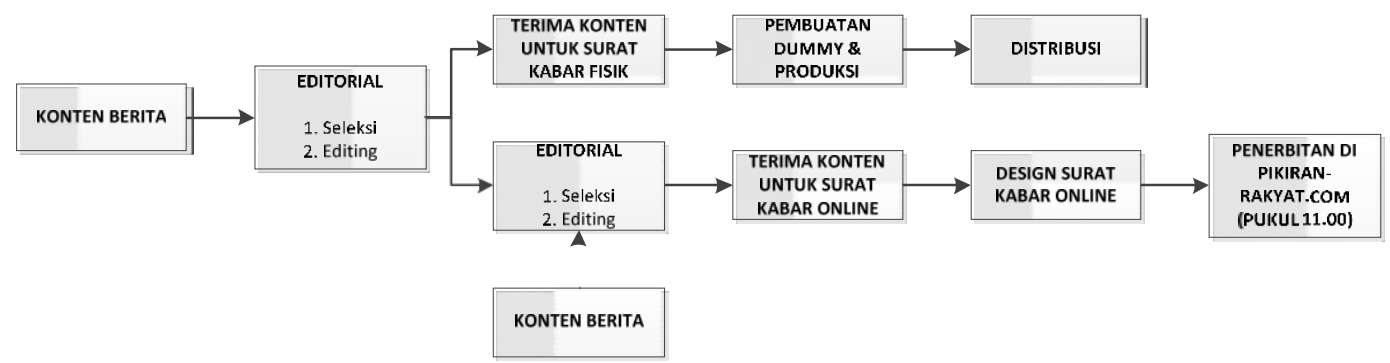

Gambar 3 Proses Operasional Surat Kabar Pikiran Rakyat

Sumber: Pikiran Rakyat, 2018

Saat ini, proses pada e newspaper Pikiran Rakyat masih merupakan cabang dari proses produksi surat kabar fisik dikarenakan konten berita yang diperoleh pun masih berpusat terhadap konten berita dari pusat. Namun demikian, e newspaper sendiri tetap menerima konten dari kontributor khusus untuk e newspaper. Namun demikian, konten tersebut pun masih melalui proses editorial di bagian e newspaper. Setelah itu, konten masuk ke bagian design di e newspaper pada pikiranrakyat.com. Pada akhir proses adalah proses penerbitan dimana sesuai dengan kebijakan perusahaan penerbitan dilakukan setiap hari pada pukul 11.00. hal tersebut dimaksudkan agar memberikan waktu terhadap surat kabar fisik melakukan penjualannya terlebih dahulu.

\section{- $\quad$ Outbound Logistics}

Proses outbound logistics merupakan proses pendistribusian e newspaper kepada konsumennya. Pikiran Rakyat saat ini melakukan distribusi melalui dua cara yaitu website pikiran-rakyat.com dan newsfeed MyEdisi.

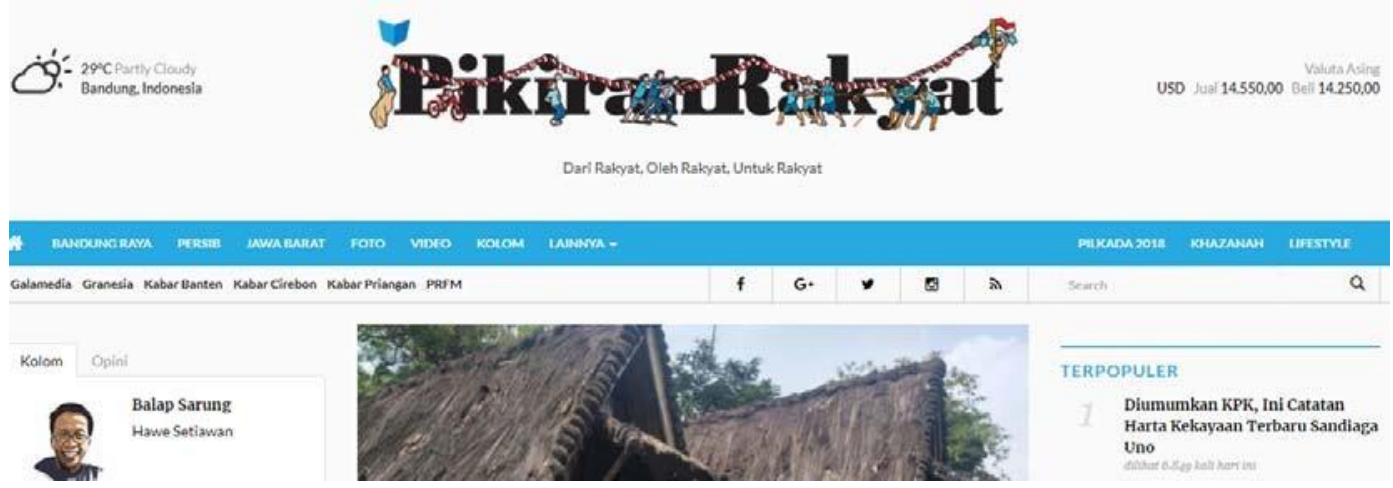

\section{Gambar 4 Website pikiran-rakyat.com}

Melalui website, e newspaper Pikiran Rakyat disebarkan yang memberikan konten berita sama dengan surat kabar fisik namun detail konten beritanya tetap ada di berita fisik. Adapun tambahan konten berita lainnya muncul dari kontributor konten berita online.

Selain itu, e newspaper Pikiran Rakyat pun disebarkan melalui newsfeed MyEdisi. Newsfeed ini merupakan aplikasi yang baru berada di google store. Newsfeed sendiri berfungsi untuk mengumpulkan sumber-sumber berita dari berbagai tempat. 


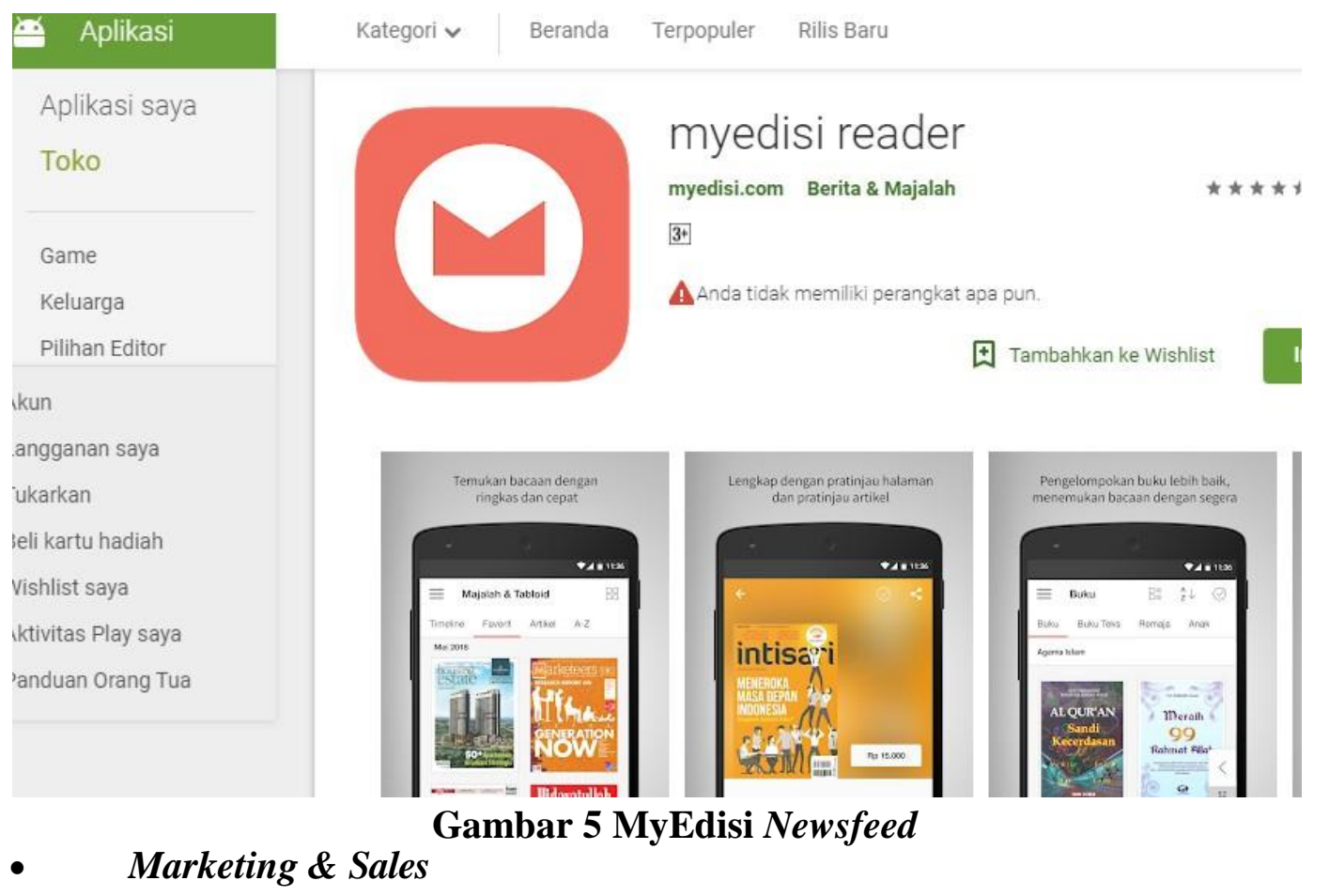

Proses marketing \& sales yang dilakukan e newspaper Pikiran Rakyat adalah dengan menggunakan search engine optimization (SEO) dan bergabung dalam newsfeed. Saat ini focus Pikiran Rakyat adalah hanya meningkatkan jumlah pembaca mereka baik dari $e$ newspaper maupun surat kabar fisik sehingga focus website pikiran-rakyat.com pun belum dipromosikan secara signifikan. Pemilihan SEO sebagai cara promosi website dikarenakan SEO merupakan salah satu alat untuk meningkatkan visibility website pada mesin pencarian google. Saat ini e newspaper Pikiran Rakyat telah memiliki rating yang baik di google yang dibuktikan dengan website mereka yang berada pada halaman awal pencarian dengan kata kunci yang berkaitan dengan Bandung. 


\begin{tabular}{llll} 
kabar bandung & @ \\
All Images News Shopping Maps More & Settings Tools \\
\hline
\end{tabular}

About $33,800,000$ results $(0.76$ seconds)

Berita Bandung Hari Ini - Kabar Terbaru Terkini | Liputan6.com

https://www.liputan6.com/tag/bandung $>$ Translate this page

Berita Bandung - Beberapa hari terakhir di Bandung dan sekitarnya terjadi hujan karena terdapat gangguan cuaca jangka pendek.

\section{BANDUNG RAYA | Pikiran Rakyat}

www. pikiran-rakyat.com/bandung-raya - Translate this page

BANDUNG, (PR)- - Terhitung sejak 15 Agustus, ada kabar baik bagi warga Kota Bandung yang

bernama Agus dan lahir tepat pada tanggal 17 Agustus. Mereka ..

Info Berita Lokal Bandung dan Jawa Barat Hari Ini - detikNews

https://news.detik.com/jawabarat - Translate this page

Info berita lokal daerah Bandung dan Jawa Barat dengan isu terkini dari politik, hukum, kriminal,

sampai peristiwa yang sedang berkembang.

\section{Gambar 6 Hasil SEO pikiran-rakyat.com}

Sumber: google.com, 2018

Hal tersebut merupakan aset berharga bagi promosi e newspaper Pikiran Rakyat dikarenakan untuk dapat mencapai hasil seperti saat ini membutuhkan usaha dan sumber daya baik materil maupun non materil yang tidak sedikit.

Bentuk promosi yang kedua adalah dengan bergabung dengan newsfeed MyEdisi. Melalui newsfeed tersebut Pikiran Rakyat berusaha untuk memperkenalkan produk mereka ke masyarakat luas.

Pikiran rakyat pun mempromosikan e newspaper melalui media social mereka seperti twitter, instagram, dan facebook.

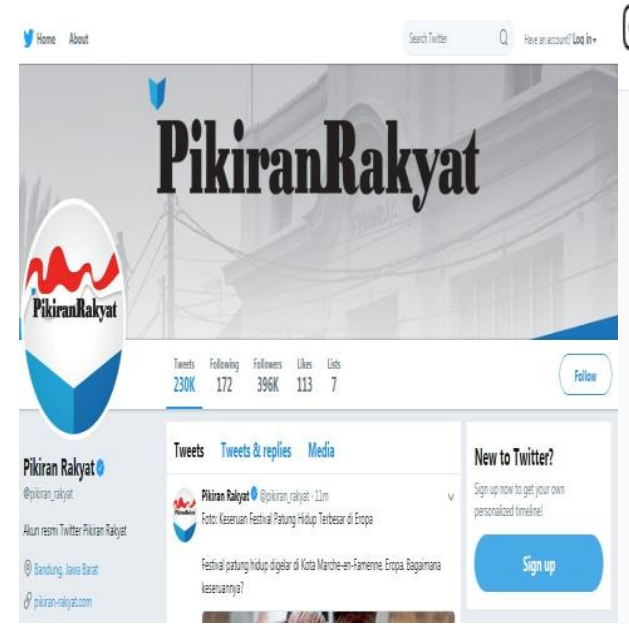

(0) Instagram

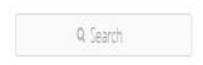

pikiranrakyat folow

1,123 posts 41.1k followers 12 following

Pikiran Rakyat

Akun Resmi Pikiran Rakyat

Facebook: www.facebook.com/pikiranrakyatonline

Twitter: pikiran_alkyat

Line: Pikiran Rakyat

\#pikiranrakyat

bitly/2v5Ml0X 


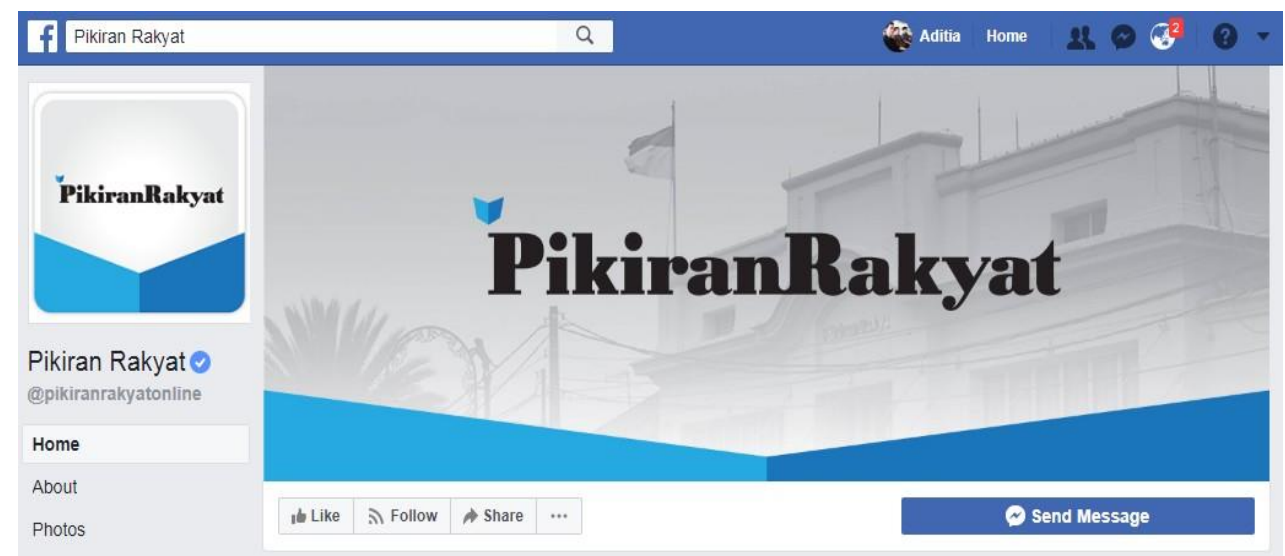

Gambar 7 Sosial Media Pikiran Rakyat

- $\quad$ Service

Berdasarkan proses bisnisnya, terdapat beberapa masalah yang perlu diperhatikan oleh e newspaper Pikiran Rakyat untuk menjaga kualitas produk mereka. Pertama, editorial dan jurnalis merupakan salah satu bagian yang paling penting dalam industri surat kabar. Hal tersebut mengacu kepada hasil riset pasar terhadap konsumen surat kabar dimana surat kabar masih diminati dikarenakan kebenaran akan konten berita yang ditampilkan. Perbedaan e newspaper dengan media online lainnya adalah adanya kode etik jurnalistik dan proses editorial yang menjaga kebenaran suatu berita. Hal tersebutlah yang menjadi daya jual e newspaper agar terus diminati oleh konsumen. Selain itu, saluran distribusi dalam menyebarkan e newspaper pun menjadi penting yang bertujuan untuk mempermudah konsumen dalam mendapatkan e newspaper tersebut. Saluran distribusi pun berfungsi untuk memperkenalkan produk ini ke masyarakat luas sehingga peran saluran distribusi tidak hanya sebagai tempat pendistribusian produk namun juga sebagai media promosi.

\section{Support Activity}

\section{- $\quad$ Firm Infrastructure}

Pikiran Rakyat saat ini secara keseluruhan telah sadar dengan fenomena bahwa surat kabar fisik penjualannya terus menurun dari tahun ke tahun. Selain itu, konsumen potensial pun mulai bergeser menjadi generasi millennial dimana generasi ini merupakan generasi yang telah terbiasa menggunakan teknologi sehingga penggunaan e newspaper merupakan salah satu cara perusahaan agar dapat bertahan di industri ini. Hal tersebut membuat Pikiran Rakyat secara perusahaan mendukung penuh pengembangan e newspaper namun dengan cara bertahap. Saat ini di Pikiran Rakyat telah berdiri divisi e newspaper yang beranggotakan 4 pegawai. Hingga saat ini masih belum ada job desc yang jelas berkenaan dengan masing-masing anggota tersebut dikarenakan Pikiran Rakyat merupakan perusahaan surat kabar yang focus terhadap konten berita bukan perusahaan teknologi yang mudah mendapatkan SDM dengan kemampuan yang mumpuni. Namun demikian, perusahaan tetap mendukung perkembangan $e$ newspaper yang ditunjukan dengan berdirinya divisi teknologi namun divisi ini masih menangani baik surat kabar fisk maupun 
e newspaper.

- Technology Development

Pikiran Rakyat merupakan perusahaan yang tetap berfokus terhadap konten berita bukan ke arah teknologi. Namun demikian usaha Pikiran Rakyat dalam mengembangkan $e$ newspaper telah serius yang ditunjukan dengan pembelian server yang diletakan di Jakarta. Namun demikian, operasional server tersebut masih menggunakan tenaga ahli dari luar perusahaan dikarenakan kekurangan SDM yang memiliki kompetensi di bidang tersebut.

\section{- Human Resource Management}

Pikiran Rakyat masih berfokus terhadap konten beritanya. Pikiran Rakyat hingga saat ini belum mempersiapkan SDM yang berfokus terhadap teknologi. Pikiran Rakyat masih memilih untuk outsource SDM dengan kompetensi teknologi.

\section{- Procurement}

Proses procurement merupakan proses pengadaan raw material dari e newspaper Pikiran Rakyat. Raw material dari e newspaper adalah konten berita. Konten tersebut diperoleh dari jurnalis dan kontributor. Selain itu ada juga kontributor khusus e newspaper. Konten berita dikumpulkan kemudian untuk menjaga kualitas konten yang akan ditayangkan merupakan kewenangan bagian editorial baik editorial umum maupun editorial untuk $e$ newspaper. Hal tersebut merupakan proses procurement untuk $e$ newspaper Pikiran Rakyat.

\section{Business Model Canvas}

Tujuan membuat model bisnis baru adalah agar dapat membuat e newspaper Pikiran Rakyat dapat berkelanjutan yang ditunjukan dengan adanya revenue stream yang lebih besar dibandingkan dengan cost structure-nya. Namun demikian hal tersebut baru dapat terukur bila model bisnis ini telah diterapkan di perusahaan. Adapun tahapan pertama adalah mengetahui revenue stream apa yang mungkin bisa muncul dalam bisnis e newspaper. Berdasarkan hasil analisis sebelumnya dapat disimpulkan dari beberapa e newspaper yang ada di Indonesia potensi revenue yang mungkin dicapai serta keterkaitannya dengan value proposition mereka. 
Tabel 2 Revenue Stream dan Value Proposioning beberapa $E$ Newspaper Indonesia

\begin{tabular}{|c|c|c|c|c|}
\hline & Bisnis Indonesia & Kompas & Republika & $\begin{array}{l}\text { Pikiran } \\
\text { Rakyat }\end{array}$ \\
\hline $\begin{array}{l}\text { Revenue } \\
\text { Stream }\end{array}$ & $\begin{array}{l}\text { - Buku (fisik } \\
\text { dan } \\
\text { e book) } \\
\text { - Web paper } \\
\text { - E-paper } \\
\text { - E-paper } \\
\text { Apps } \\
\text { - Data } \\
\text { Keuangan } \\
\text { - Laporan } \\
\text { Bisnis } \\
\text { - Analisa } \\
\text { Pakar }\end{array}$ & $\begin{array}{l}\text { - Buku } \\
\text { (fisik } \\
\text { dan } E \\
\text { book) } \\
\text { - Tiket } \\
\text { - Foto } \\
\text { - E paper } \\
\text { - Ce } \\
\text { ndera } \\
\text { Mata }\end{array}$ & $\begin{array}{l}\text { - E paper } \\
\text { - Foto } \\
\text { - Kliping } \\
\text { - Al } \\
\text { Quran } \\
\text { Digita } \\
1\end{array}$ & $\begin{array}{l}\text { Hingga } \\
\text { wawancara } \\
\text { dilakukan } \\
\text { belum ada } \\
\text { revenue } \\
\text { stream }\end{array}$ \\
\hline $\begin{array}{l}\text { Value } \\
\text { Proposition }\end{array}$ & $\begin{array}{l}\text { Surat kabar } \\
\text { harian dengan } \\
\text { konten bisnis } \\
\text { yang } \\
\text { terpercaya }\end{array}$ & $\begin{array}{l}\text { Surat } \\
\text { kabar } \\
\text { dengan } \\
\text { berita } \\
\text { berimban } \\
\text { g, } \\
\text { kredibel } \\
\text { dan } \\
\text { indepen }\end{array}$ & $\begin{array}{l}\text { Surat kabar } \\
\text { Republika } \\
\text { mengedepanka } \\
\text { n konten yang } \\
\text { berfokus } \\
\text { terhadap } \\
\text { komunitas } \\
\text { muslim di } \\
\text { Indonesia }\end{array}$ & $\begin{array}{l}\text { Surat kabar } \\
\text { dengan } \\
\text { konten } \\
\text { Bandung } \\
\text { Raya, Persib } \\
\text { dan Jawa } \\
\text { Barat }\end{array}$ \\
\hline
\end{tabular}

Tabel di atas menunjukan bahwa terdapat beberapa pilihan revenue stream yang telah dijalankan oleh beberapa e newspaper di Indonesia. Hal tersebut dapat menjadi pertimbangan sebagai potensial revenue stream bagi Pikiran Rakyat. Maka rekomendasi penelitian ini terhadap bisnis model e newspaper Pikiran Rakyat dapat dilihat pada gambar di bawah ini.

\begin{tabular}{|l|l|c|l|l|}
\hline $\begin{array}{l}\text { Key } \\
\text { Partnersh } \\
\text { ips }\end{array}$ & $\begin{array}{l}\text { Key } \\
\text { Activities }\end{array}$ & $\begin{array}{c}\text { Value } \\
\text { Propositions } \\
\text { Untuk }\end{array}$ & $\begin{array}{l}\text { Customer } \\
\text { Relations } \\
\text { hips }\end{array}$ & $\begin{array}{l}\text { Customer } \\
\text { Segments }\end{array}$ \\
\hline & & & \\
\hline
\end{tabular}




\begin{tabular}{|c|c|c|c|c|}
\hline $\begin{array}{l}\text { Advertising agencies } \\
\text { News/ Content } \\
\text { aggregator } \\
\text { Communities and } \\
\text { partner } \\
\text { Social network sites } \\
\text { (Instagram, Facebook, } \\
\text { Twitter, LINE, } \\
\text { Snapchat, Steller, } \\
\text { Youtube) } \\
\text { Hosting dan Domain } \\
\text { provider }\end{array}$ & $\begin{array}{l}\text { Memastikan } \\
\text { discoverabilit } \\
\text { y konten } \\
\text { Pengembanga } \\
\text { n website } \\
\text { Key } \\
\text { Resources } \\
\text { Jurnalis/ } \\
\text { kontributo } \\
\text { r } \\
\text { Tim } \\
\text { editorial } \\
\text { Page rank } \\
\text { website } \\
\text { pikiran- } \\
\text { rakyat.co } \\
\text { m } \\
\text { Brand } \\
\text { Pikiran } \\
\text { Rakyat } \\
\text { Server } \\
\text { Kepemilikan } \\
\text { PR FM }\end{array}$ & $\begin{array}{c}\text { Pay per } \\
\text { performance } \\
\text { cost based } \\
\text { The most value } \\
\text { price dengan } \\
\text { bundling } \\
\text { advertisement } \\
\text { dan jaminan } \\
\text { terpenuhinya } \\
\text { KPI } \\
\text { Untuk } \\
\text { audience: } \\
\text { Konten } \\
\text { Bandung Raya, } \\
\text { Persib, dan } \\
\text { Jawa Barat } \\
\text { yang } \\
\text { terpercaya } \\
\text { sesuai kode } \\
\text { etik }\end{array}$ & $\begin{array}{l}\text { Distribution } \\
\text { Channels } \\
\text { Untuk } \\
\text { advertiser: } \\
\text { Personal } \\
\text { company } \\
\text { representative } \\
\text { Untuk audience: } \\
\text { Social Media } \\
\text { Website News } \\
\text { Agregator }\end{array}$ & $\begin{array}{c}\text { Adver } \\
\text { tiser: } \\
\text { Corpo } \\
\text { rates } \\
\text { UMKM } \\
\text { Personal } \\
\text { Pemerin } \\
\text { tahan } \\
\\
\text { Audience: } \\
\text { Masyarakat } \\
\text { generasi } \\
\text { milenial } \\
\text { berusia 17-35 } \\
\text { tahun } \\
\text { Masyarakat } \\
\text { pengguna } \\
\text { surat kabar } \\
\text { fisik dengan } \\
\text { behavior } \\
\text { berpindah ke } \\
\text { digital } \\
\text { berusia > 35 } \\
\text { tahun }\end{array}$ \\
\hline
\end{tabular}




\begin{tabular}{|c|c|}
\hline Cost Structures Gaji & Revenue Streams \\
Infrastruktur IT & Iklan Digital \\
Marketing dan Promosi Fee & Soft Sales \\
Kontributor & Promotion \\
& (Artikel) \\
& Advertorial \\
& Obituary \\
& Cendera mata sesuai dengan value \\
proposition & Foto \\
\hline & Kliping \\
& E Paper \\
\hline
\end{tabular}

Gambar 8 Rekomendasi Bisnis Model E Newspaper Pikiran Rakyat

Pikiran Rakyat perlu menentukan terlebih dahulu revenue stream yang mungkin diperoleh. Terdapat tiga potensi revenue yaitu iklan digital, soft sales promotion dan advertorial. Soft sales promotion dan advertorial merupakan turunan dari media placement pada revenue stream PT Infia Media Pramata. Kedua jenis revenue tersebut berfokus terhadap soft selling dimana iklan disatukan dengan salah satu konten artikel ataupun dengan membuat artikel tersendiri yang membahas suatu produk. Sedangkan iklan digital merupakan penempatan iklan selayaknya surat kabar fisik dan juga ditambah dengan penempatan iklan pada space yang tersedia di halaman muka pikiran-rakyat.com. Selain itu, pada e paper sendiri bisa ditambahkan space iklan pada saat audience memilih suatu konten dengan mengklik header dari judul. Selain itu, hingga saat ini obituary atau berita duka atas seseorang masih ramai digunakan pada surat kabar fisik. Hal tersebut pula dapat dikembangkan di e newspaper sehingga tidak ada potensi revenue yang mungkin hilang dari surat kabar fisik.

Secara commerce, Pikiran Rakyat dapat berfokus terhadap produk-produk yang di minati di Jawa Barat khususnya di Bandung. Cenderamata dapat menjadi salah satu pilihan sebagai produk yang dapat dijual. Selain itu, foto dan kliping pun dapat menjadi pilihan mengacu kepada yang telah dilakukan oleh e newspaper lainnya di Indonesia. Yang terakhir, Pikiran Rakyat perlu untuk fokus kepada Persib dikarenakan pembahasan Persib di Pikiran Rakyat merupakan konten yang paling diminati. Produk-produk yang berkaitan dengan Persib dapat menjadi produk potensial sebagai pendongkrak revenue. Hal tersebut merupakan potensi- potensi yang mungkin dikembangkan oleh Pikiran Rakyat dalam menciptakan revenue dari e newspaper Pikiran Rakyat. 


\section{KESIMPULAN}

E-newspaper Pikiran Rakyat memiliki potensi yang besar untuk dikembangkan. Hal tersebut merupakan suatu keunggulan kompetitive bagi perusahaan agar dapat bertahan di industri surat kabar. Namun demikian, Pikiran Rakyat perlu focus terhadap pengembangan $e$-newspaper dan membuat e-newspaper menjadi calon pengganti surat kabar cetak di masa yang akan datang. Mengacu kepada hasil penelitian, ditemukan bahwa formulasi revenue stream harus mengacu kepada value proposition yang telah ditetapkan di awal bisnis model. Formulasi value proposition perlu memperhatikan resource dan kapabilitas dari perusahaan tersebut sehingga value proposition dapat memiliki image yang kuat di mata konsumen. Hasil penelitian menemukan bahwa terdapat beberapa pilihan revenue stream yang dapat dioptimalkan oleh e- newspaper Pikiran Rakyat yaitu:

Iklan Digital

1. Soft Sales Promotion (Artikel)

2. Advertorial

3. Obituary

4. Cendera mata sesuai dengan value proposition

5. Foto

6. Kliping

7. E Paper

\section{REFERENSI}

Abdollahi, G., \& Leimstoll, U. (2011). A Classification for Business Model Types in Ecommerce. AMCIS 2011 Proceedings All Submissions, 88.

Ensign, P. C. (2001). Value Chain Analysis and Competitive Advantage: Assessing Strategic Linkages and Interrelationships. Journal of General Management, 27(1), 18-42.Retrieved from https://pdfs.semanticscholar.org/d0cd/9f9a36d579afe611f12db0385788f28aadf5.pdf

Flavian, C., Gurrea, R., \& Orús, C. (2009). Web design: a key factor for the website success. Journal of Systems and Information Technology, 11(2), 168-184. https://doi.org/https://doi.org/10.1108/13287260910955129

Mullins, J., \& Komisar, R. (2009). Getting to Plan B Breaking Through to a Better Business Model. Massachusetts: Harvard Business Press. Retrieved from http://library.globalchalet.net/Authors/Startup Collection/\%5BMullins and Komisar, 2009\%5D Getting to Plan B - Breaking Through to a Better Business Model.pdf

Nielsen. (2015). Newspaper and Magazine Readership. Retrieved from https://www.nielsen.com/nz/en/press-room/2015/newspaper-and-magazine-readership- $\quad$ q12015.html

Osterwalder, A., \& Pigneur, Y. (2010). Business Model Generation: A Handbook for Visionaries, Game Changers, and Challengers. John Wiley \& Sons.

Ottosen, R., \& Krumsvik, A. H. (2012). Digital Challenges on the Norwegian Media 


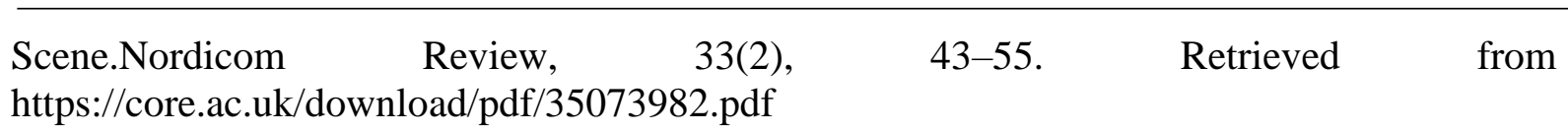

Pearce, J. A., \& Robinson, R. B. (2008). Manajemen Strategis, Formulasi, Implementasi dan Pengendalian. Jakarta: Salemba Empat.

Rappa, M. (2010). Business Models on the Web. Retrieved from http://digitalenterprise.org/models/models.html\#Merchant

Republika. (2011). SPS:Pembaca Koran Tinggal 15 Persen. Retrieved from https://www.republika.co.id/berita/nasional/umum/11/10/21/ltf33z-spspembaca-koran- tinggal-15persen

Soltani, S. (2012). STRATEGIC MARKETING PLAN IN PRODUCT LIFE CYCLE (More Profitability in Stages of Product Life Cycling) Case; PLC of HP and ACER laptop. VAASAN AMMATTIKORKEAKOULU UNIVERSITY OF APPLIED SCIENCES. Retrieved from https://www.theseus.fi/bitstream/handle/10024/47037/plc tez.pdf?sequence=1

Štefan, S., \& Richard, B. (2014). Analysis of Business Models. Journal of Competitiveness, 6(4), 19-40. https://doi.org/10.7441/joc.2014.04.02

Sun, Y.-S., \& Guo, S. (2004). Media Use, Social Comparison, Cognitive Dissonance and Peer Pressure as Antecedents of Fashion Involvement. Media Use, Social Comparison, Cognitive Dissonance and Peer Pressure as Antecedents of Fashion Involvement.Retrieved from https://web.uri.edu/iaics/files/10Yan-Shu-Sun-Steve-Guo.pdf

Teece, D. J. (2010). Business Models, Business Strategy and Innovation. Elsevier Ltd. https://doi.org/10.1016/j.lrp.2009.07.003

Vanhaverbeke, W., \& Chesbrough, H. (2012). A Classification of Open Innovation and Open BusinessModels.Retrievedfromhttps://www.researchgate.net/profile/Wim_Vanhaverbeke/public ation/266737917_A_Classification_of_Open_Innovation_and_Open_Business_Models/links/5 43a344c0cf2d6 698be1730e/A-Classification-of-Open-Innovation-and-Open-BusinessModels.pdf 